\title{
Polymorphic Ventricular Tachycardia with QT Interval Prolongation Due to a Brain Tumor
}

\author{
Yui Nakayama ${ }^{1}$, Toshiyuki Furukawa ${ }^{2}$, Marika Yamada ${ }^{1}$, Makoto Takano ${ }^{1}$, \\ Ikutaro Nakajima ${ }^{1}$, Tomoo Harada ${ }^{1}$ and Yoshihiro $\mathrm{J} \mathrm{Akashi}^{1}$
}

\begin{abstract}
:
We herein report the case of a 20-year-old man with a history of epilepsy who presented with frequent transient loss of consciousness (T-LOC) and polymorphic ventricular tachycardia (VT) with QT interval prolongation. Blood investigations revealed panhypopituitarism. Following a biopsy, he was diagnosed with brain germinoma. During the biopsy, he had an episode of polymorphous VT with QT prolongation. There was no recurrence of T-LOC following chemotherapy and hormone replacement therapy. This case indicates the importance of checking the QT interval in patients with T-LOC, including those with seizures and brain tumors, to ensure appropriate treatment.
\end{abstract}

Key words: ventricular tachycardia, QT prolongation, brain tumor

(Intern Med 60: 2633-2637, 2021)

(DOI: 10.2169/internalmedicine.6635-20)

\section{Introduction}

Long QT syndrome (LQTS) can be congenital or acquired. The causes of acquired LQTS are diverse, including drugs, metabolic and electrolyte abnormalities, heart disease, and central nervous system disorders. Electrolyte abnormalities include hypokalemia, hypomagnesemia, and hypocalcemia. Hypopituitarism might lead to electrolyte abnormalities, and there are several reports of loss of consciousness due to hypopituitarism (1-3).

We herein report a case of QT prolongation caused by electrolyte abnormalities associated with hypopituitarism due to a pituitary tumor.

\section{Case Report}

A 20-year-old man with a history of epilepsy was diagnosed with a brain tumor and referred to our neurosurgical department for treatment. He began to experience episodes of transient loss of consciousness (T-LOC) for 1 year and 3 months almost twice a week despite taking antiepileptic drugs (Sodium valproate $800 \mathrm{mg}$, and Levetiracetam 1,000 $\mathrm{mg}$ ). These episodes occurred both at rest and during exercise. An electrocardiogram (ECG) abnormality had been noted in his records two years before the onset of T-LOC. A pituitary tumor was identified on magnetic resonance imaging (MRI), and he was subsequently referred to the neurosurgery department for a biopsy. He had no family history of sudden death or structural heart disease.

On admission, his ECG (Fig. 1) showed sinus rhythm with a heart rate of 60 beats per minute, and the corrected QT (QTc) interval was prolonged to $519 \mathrm{~ms}$. An echocardiogram showed a normal ventricular function with no structural heart disease. Blood investigations (Table) revealed panhypopituitarism, including hypopituitarism, hypoadrenalism, and hypothyroidism. He had hypokalemia at the time of admission but recovered spontaneously without treatment (Fig. 2).

MRI revealed a pituitary tumor that the brain tumor was an intraceller component and pineal gland (Fig. 3), and a neurosurgeon performed an endoscopic biopsy of the tumor under local anesthesia. Later, his ECG showed a prolonged QT interval and ventricular (or atrial) bigeminy, and torsade de pointes (TdP) developed following single premature ventricular contractions (PVCs) in the short-long-short se-

${ }^{1}$ Division of Cardiology, Department of Internal Medicine, St. Marianna University School of Medicine, Japan and ${ }^{2}$ Syncope Unit, Toyoko Hospital, St. Marianna University School of Medicine, Japan 

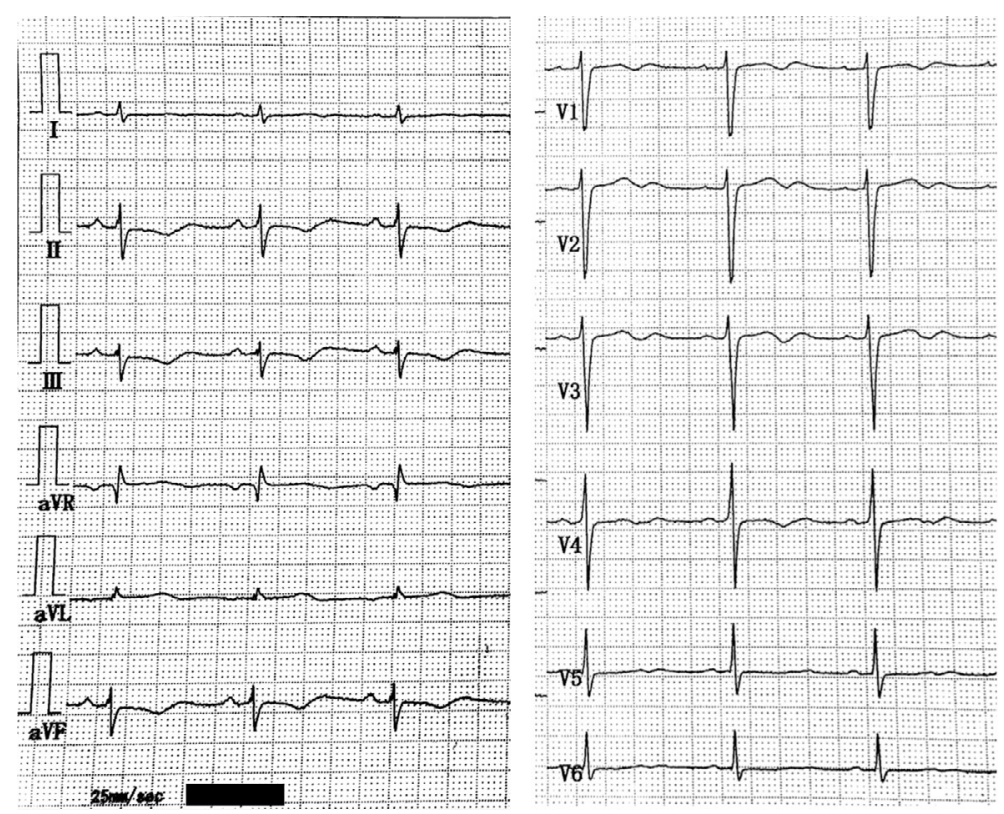

Figure 1. His electrocardiogram on admission showed sinus rhythm with a heart rate of 60 times, and the corrected QT interval prolonged to $519 \mathrm{~ms}$. QRS complexes were without any abnormality.

Table. Patient's Laboratory Data.

\begin{tabular}{|c|c|c|c|}
\hline Laboratory data on admission & & & \\
\hline \multicolumn{4}{|l|}{ Complete blood count } \\
\hline White blood cells & $6,800 / \mu \mathrm{L}$ & & \\
\hline Red blood cells & $380 \times 10^{\wedge} 4 / \mu \mathrm{L}$ & & \\
\hline Hemoglobin & $11.8 \mathrm{~g} / \mathrm{dL}$ & & \\
\hline Platelets & $109 \times 10^{\wedge} 3 / \mu \mathrm{L}$ & & \\
\hline \multicolumn{4}{|l|}{ Blood chemistry analysis } \\
\hline Blood urea nitrogen & $3.4 \mathrm{mg} / \mathrm{dL}$ & & \\
\hline Creatinine & $0.86 \mathrm{mg} / \mathrm{dL}$ & & \\
\hline Sodium & $145 \mathrm{mEq} / \mathrm{L}$ & & \\
\hline Potassium & $3.3 \mathrm{mEq} / \mathrm{L}$ & & \\
\hline Chloride & $108 \mathrm{mEq} / \mathrm{L}$ & & \\
\hline Creatinine kinase & $114 \mathrm{U} / \mathrm{L}$ & & \\
\hline Aspartate aminotransferase & $28 \mathrm{U} / \mathrm{L}$ & & \\
\hline Alanine aminotransferase & $25 \mathrm{U} / \mathrm{L}$ & & \\
\hline Total billirubin & $0.5 \mathrm{mg} / \mathrm{dL}$ & & \\
\hline Plasma Glucose & $93 \mathrm{mg} / \mathrm{dL}$ & & \\
\hline \multicolumn{4}{|l|}{ Endocrine Data } \\
\hline Piruirary gland & & Adrenal grand & \\
\hline $\mathrm{GH}$ & $0.038 \mathrm{ng} / \mathrm{mL}$ & Cortisol & $0.7 \mu \mathrm{g} / \mathrm{dL}$ \\
\hline IGF-1 & $55 \mathrm{ng} / \mathrm{mL}$ & PRA & $0.2 \mathrm{mg} / \mathrm{mL} / \mathrm{hr}$ \\
\hline АCTH & $<0.1 \mathrm{pg} / \mathrm{mL}$ & Aldosterone & 53 ng.dL \\
\hline LH & $<0.07 \mathrm{~m} \mu \mathrm{U} / \mathrm{mL}$ & DHEA-S & $<5 \mathrm{ng} / \mathrm{mL}$ \\
\hline FSH & $<0.30 \mathrm{~m} \mu \mathrm{U} / \mathrm{mL}$ & Testosterone & $<0.04 \mathrm{ng} / \mathrm{dL}$ \\
\hline $\mathrm{ADH}$ & $<0.8 \mathrm{pg} / \mathrm{mL}$ & Thiroid & \\
\hline PRL & $36.63 \mathrm{ng} / \mathrm{mL}$ & FT3 & $1.2 \mathrm{pg} / \mathrm{mL}$ \\
\hline TSH & $7.395 \mu \mathrm{U} / \mathrm{mL}$ & FT4 & $0.5 \mathrm{ng} / \mathrm{dL}$ \\
\hline
\end{tabular}

quence. The patient lost consciousness during TdP, from which he recovered spontaneously (Fig. 4). Cardiac ultrasound performed immediately after TdP did not reveal any obvious abnormal wall movement, and acute coronary syn- drome was denied. He was then diagnosed with biopsyproven germinoma.

The patient was prescribed carboplatin, etoposide, and hormone replacement therapy. At the six-month follow-up 


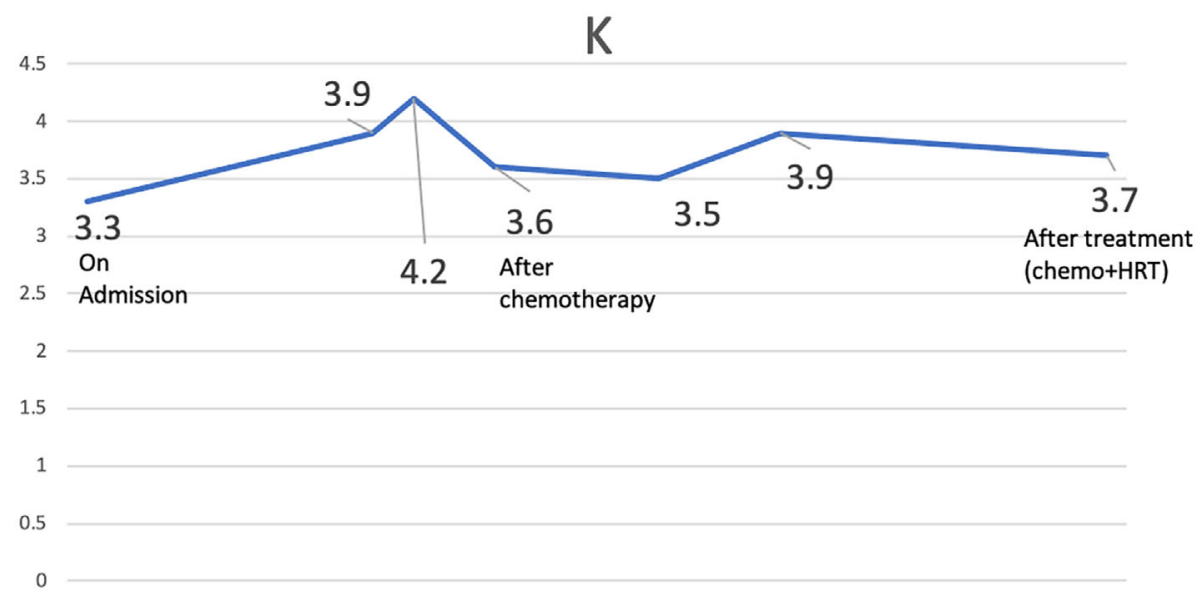

Figure 2. Change in serum potassium. He had hypokalemia at the time of admission, but he recovered spontaneously without treatment.

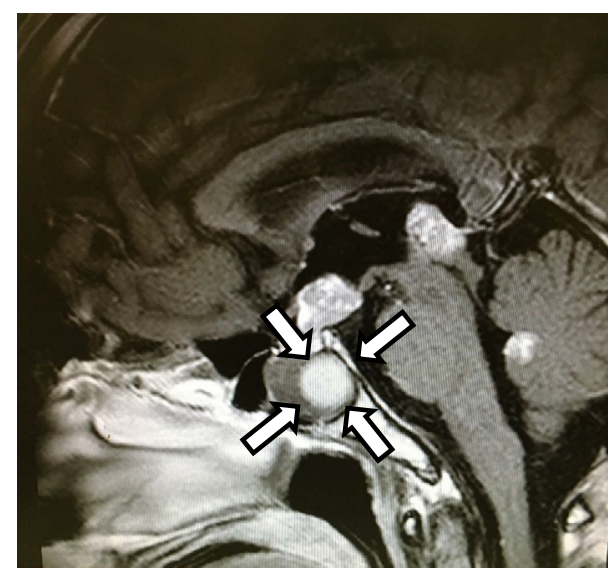

Figure 3. The sagittal magnetic resonance imaging of the brain showed the pituitary tumor (among white arrows).

examination, his tumor had reduced in size; however, the panhypopituitarism persisted, and hormone replacement therapy was continued. The QTc interval had shortened from 519 to $418 \mathrm{~ms}$ (Fig. 5), and no more syncopal episodes were reported.

Due to these results, the syncope was attributed to TdP due to prolonged LQTS caused by the brain tumor.

\section{Discussion}

The exact mechanism underlying QT interval prolongation is currently unknown. However, there have been several reports of hypopituitarism causing prolonged QT. There are three main hypotheses concerning how hypopituitarism might cause prolonged QT. First, cortisol deficiency has been shown to cause K-channel down-regulation, resulting in repolarization disorder and increasing a patient's susceptibility to fatal arrhythmias, such as TdP (4). Second, cortisol deficiency results in down-regulation of calcium transporter, resulting in increased intracellular $\mathrm{Ca}$ concentration and leading to abnormalities in the repolarization process, which then manifests as a prolonged QT interval (5). Third, cortisol deficiency causes hypomagnesemia. Prolonged hypomagnesemia depletes intracellular $\mathrm{K}$, resulting in hypokalemia (6).

One of the causes of acquired LQTS is a cerebrovascular disorder, such as subarachnoid hemorrhaging; however, QT prolongation due to a cerebrovascular disorder is induced by an autonomic imbalance and hyperactivity of the sympathetic nervous system coupled with increased intracranial pressure $(7,8)$.

We speculate that germinoma may cause QT prolongation through panhypopituitarism, specifically hypothyroidism and decreased levels of adrenocorticotropic hormone (ACTH). After chemotherapy for germinoma and hormone replacement therapy for panhypopituitarism, the present patient had no recurrence of T-LOC despite taking no drugs, such as $\beta$ blockers or potassium supplementation.

This case report has two limitations. First, Takotsubo cardiomyopathy could not be completely ruled out because the electrocardiogram showed changes under stress. However, this diagnosis is unlikely because there was no chest pain, and no abnormal wall movements were seen on echocardiography. Second, we did not perform any investigations to check for genetic abnormalities. However, since there was no family history of sudden death, and hormone replacement therapy improved the ECG abnormalities, it is unlikely that QT prolongation was due to genetic abnormalities.

\section{Conclusion}

We herein report a man with a pituitary tumor who presented with QT elongation and chronic T-LOC. Brain tumors might cause QT prolongation through panhypopituitarism; patients with brain tumors presenting with T-LOC might therefore have cardiogenic syncope. Physicians should check the QTc interval of all patients presenting with TLOC to rule out underlying conditions, such as panhypopituitarism. 


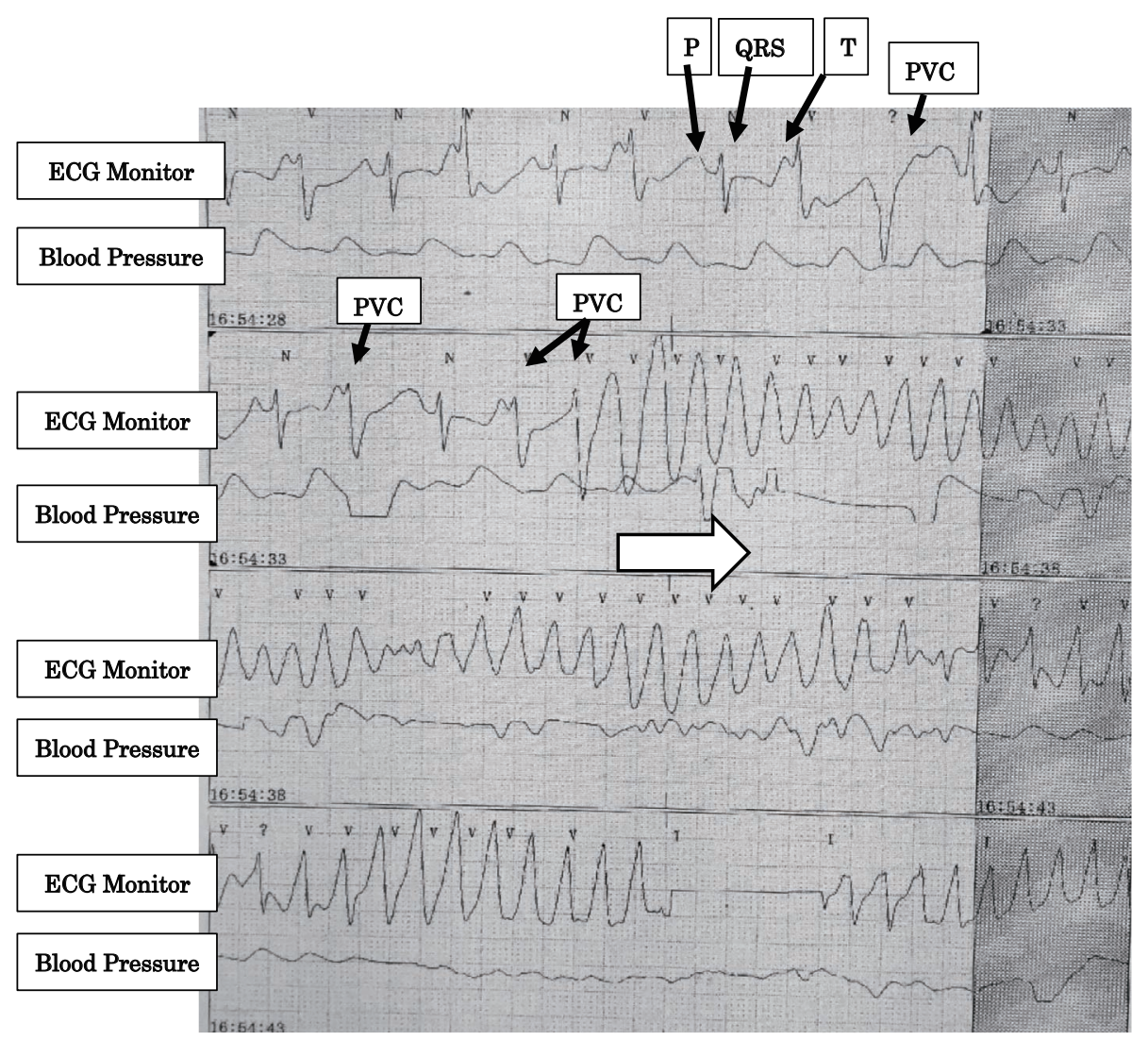

Figure 4. The electrocardiogram monitor during surgical operation. The monitor showed prolonged QT interval and ventricular (or atrial) bigeminy, and a torsade de pointes (TdP) developed subsequent to single PVC on the short-long-short sequence. The blood pressure was fall down at the same time as TdP started.

1) QTc $519 \mathrm{~ms}$

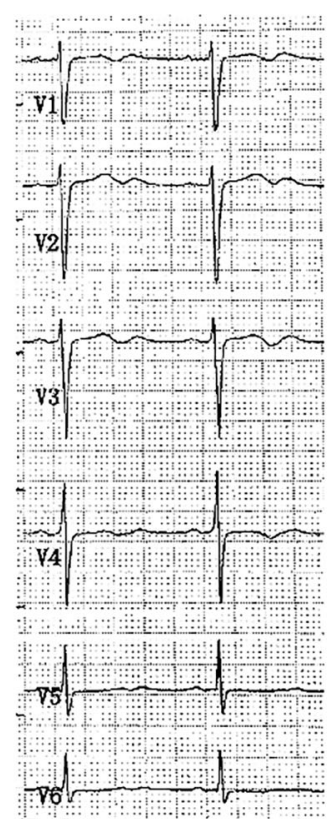

2) $559 \mathrm{~ms}$
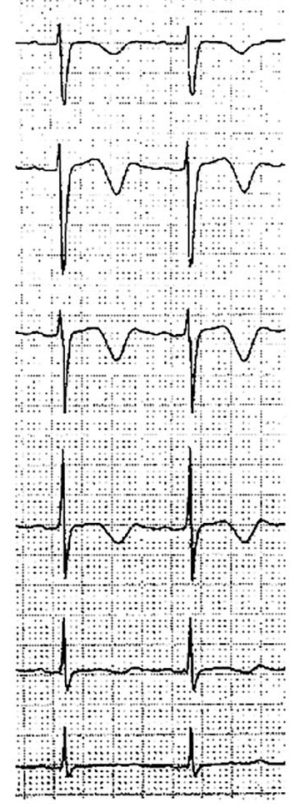

3) $556 \mathrm{~ms}$

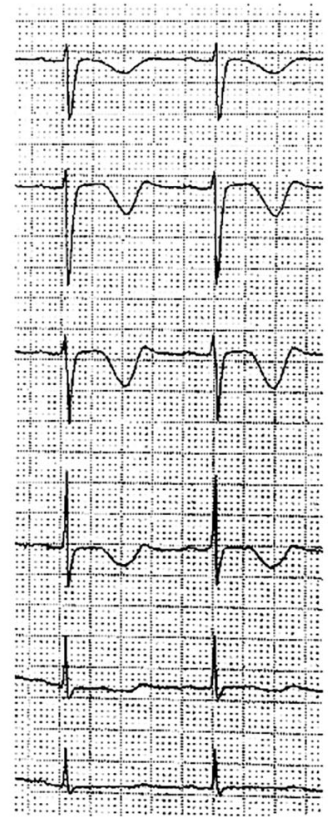

4) $418 \mathrm{~ms}$

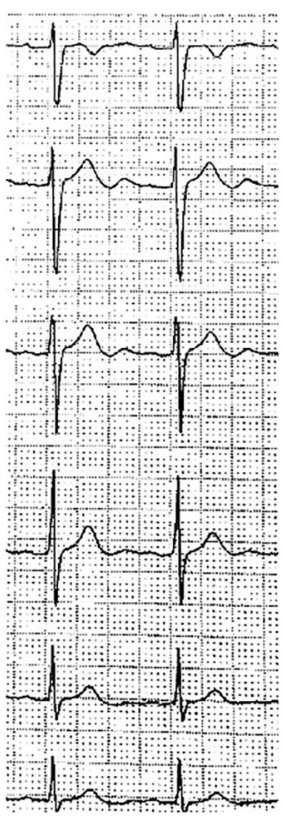

Figure 5. The corrected QT (QTe) interval improved from $519 \mathrm{~ms}$ on the admission to $418 \mathrm{~ms}$ after the chemotherapy. 1) On admission, 2) Just after TdP/Before Chemotherapy, 3) A few days after biopsy, 4) After the chemotherapy and the hormone replacement therapy. 
The authors state that they have no Conflict of Interest (COI).

\section{References}

1. Sueuchi T, et al. A case of panhypopituitarism detected by repeated loss of consciousness. Tokushima Red Cross Hospital Medical Journal 16: 68-72, 2011.

2. Arpaci D, Demir MV, Garip T, Tamer A. A case of QT prolongation associated with panhypopituitarism. Case Rep Endocrinol 2013: 989745, 2013.

3. Kang DG, Kim SE, Park MS, et al. Acquired long QT syndrome manifesting with torsades de pointes in a patient with panhypopituitarism due to radiotherapy. Korean Circ J 43: 340-342, 2013.

4. Takimoto K, Levitan ES. Glucocorticoid induction of kv1.5 K+ channel gene expression in ventricle of rat heart. Circ Res 75: 1006-1013, 1994.
5. Narayanan N. Effects of adrenalectomy and in vivo administration of dexamethasone on ATP-dependent calcium accumulation by sarcoplasmic reticulum from rat heart. J Mol Cell Cardiol 15: 715, 1983.

6. Iga K, Hori K, Gen H. Deep negative $\mathrm{T}$ waves associated with reversible left ventricular dysfunction in acute adrenal crisis. Heart Vessels 7: 107-111, 1992.

7. Perron AD, Brady WJ. Electrocardiographic manifestations of CNS events. Am J Emerg Med 18: 715-720, 2000.

8. Chao CL, Wu CC, Lee YT. Torsade de pointes and T-wave alternans in a patient with brain stem hemorrhage. Int J Cardiol 51: 199-202, 1995.

The Internal Medicine is an Open Access journal distributed under the Creative Commons Attribution-NonCommercial-NoDerivatives 4.0 International License. To view the details of this license, please visit (https://creativecommons.org/licenses/ by-nc-nd/4.0/).

(C) 2021 The Japanese Society of Internal Medicine Intern Med 60: 2633-2637, 2021 